\section{Elektronische Gesundheitskarte \\ KBV pocht auf Beteiligung der Kassen}

—Die neuen Pläne zur elektronischen Gesundheitskarte (eGK) und zur Online-Anbindung der Ärzte sind bei Ärzten und Krankenkassen auf ein unterschiedliches Echo gestoßen.

Nach einem Antrag der Koalitionsfraktionen zum GKV-Änderungsgesetz soll der Online-Abgleich der Versichertenstammdaten gesetzlich festgeschrieben werden. Die Kassenärztliche Bundesvereinigung (KBV) kritisierte das Vorhaben: „Die verpflichtende Online-Anbindung halten wir für einen Freien Beruf nicht für sachgerecht“, sagte Pressesprecher Dr. Roland Stahl auf Anfrage.

Für die Akzeptanz der Karte bei Ärzten seien die Anreize entscheidend. Stahl: „Nötig ist vor allem eine angemessene Beteiligung der Krankenkassen an den Kosten. "Eine OnlineAnbindung der Vertragsärzte halte auch die KBV generell für wichtig, so Stahl. Die KBV hofft jetzt darauf, bald mit den Kassen über eine Vereinbarung ins Gespräch zu kommen. Der GKV-Spitzenverband begrüßte, dass „die verpflichtende Online-Anbindung nun gesetzlich festgelegt" werden soll. „Nur durch die Online-Prüfung und Aktualisierung der elektronischen Gesundheitskarte wird das Ziel, die Datensicherheit zu erhöhen und Kartenmissbrauch zu vermeiden, tatsächlich erreicht“ , sagte Claudia Widmaier vom GKV-Spitzenverband der Ärzte Zeitung.

ger

\title{
Gute Benotung
}

\section{Die Deutschen mögen ihren Arzt}

— Internetportale, in denen Patienten ihren Doktor benoten, sorgten vor einiger Zeit für großen Aufruhr und werden von Ärzten mit einem gewissen Misstrauen beäugt. Mittlerweile hat sich die Aufregung etwas gelegt, und die erste aktuelle Bilanz zeigt, dass die anfänglichen Befürchtungen nicht im entferntesten eingetroffen sind. Im Gegenteil: Die Auswertung von ca. 32.00o Bewertungen im Ärzteportal jameda zeigt jetzt, dass die Bundesbürger ihren Ärzten gegenüber doch recht wohlwollend eingestellt sind.

Behandlungserfolg, Freundlichkeit, Aufklärungsumfang und die Zeit, die der Arzt sich für seine Patienten genommen hatte, wurden mit Schulnoten von eins bis sechs benotet. Die niedergelassenen Ärzte erhielten von den Kassenpatienten eine glatte 2 und von den Privatpatienten eine 1,8.

Lediglich in Berlin zeigte sich eine Diskrepanz: Hier weicht die Zufriedenheit der Privatpatienten signifikant von der der Kassenpatienten ab: Privat erhalten die Berliner Doktores eine 1,6, auf Kasse eine 2,3.

red

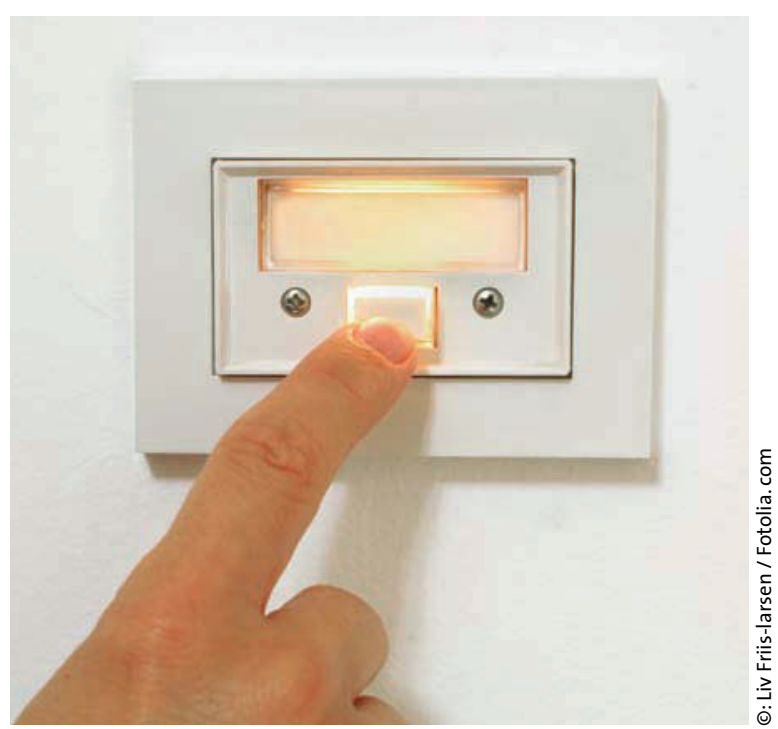

Taube und sehr schwerhörige Menschen brauchen statt einer Türglocke ein optisches Signal.

\section{Leistungspflicht der Krankenkasse}

\section{Hört ein Schwerhöriger die Türklingel nicht ...}

_.... muss die gesetzliche Krankenkasse eine Lichtsignalanlage finanzieren, urteilte kürzlich das Bundessozialgericht. Der Fall: Ein hochgradig schwerhöriger Patient hatte eine Lichtsignalanlage beantragt, weil er nicht (mehr) hören konnte, wenn Besuch an seiner Wohnungstür klingelte. Die gesetzliche Krankenversicherung lehnte die Kostenübernahme dafür jedoch ab und verwies auf die Pflegekasse: Der Einbau einer Lichtsignalanlage verbessere das individuelle Wohnumfeld, für solche Maßnahmen sei die Pflegeversicherung zuständig.

Damit war das Bundessozialgericht nicht einverstanden (B 3 KR 5/og R, Urteil vom 29. April 2010). So eine Anlage sei nicht fest mit dem Gebäude verbunden. Sie könne in jeder anderen Wohnung unverändert eingesetzt werden und falle daher nicht in die Zuständigkeit der Pflegekasse.

Die gesetzliche Krankenversicherung müsse behinderte Menschen mit Hilfsmitteln versorgen, die sie benötigten, um ihre Behinderung und deren Folgen auszugleichen. Im konkreten Fall sei der Versicherte so schwerhörig, dass es an Taubheit grenze. Er könne trotz eines guten Hörgeräts die Wohnungsklingel nicht mehr wahrnehmen. Daher müsse die Krankenkasse die Kosten für eine Lichtsignalanlage tragen.

So eine Anlage besteht aus einem (oder mehreren) Empfänger und einem Sender. Der Sender wird per Kabel mit der Türklingel verbunden, nimmt die akustischen Signale der Klingel auf und macht daraus Funkimpulse. Diese Impulse werden über Steckdose und Stromnetz zum Empfänger übertragen: Das ist eine Blitzlampe, welche die Funkimpulse in Lichtsignale umwandelt. 